\title{
Evaluation of Kidney Function and Structure in Potential Living Kidney Donors: Implications for the Donor and Recipient
}

\author{
Ziad S. Zaky • Surafel Gebreselassie • Emilio D. Poggio
}

Published online: 30 January 2015

(C) Springer International Publishing AG 2015

\begin{abstract}
Kidney transplantation is the best treatment for patients with end-stage renal disease and recipients of living kidney donors fare better than recipients of deceased donors. In view of the shortage of organ supply and the long waiting list, expansion of the living donor pool has been sought. Importantly, donor acceptance criteria must first and foremost be grounded in concerns for donor safety. Recent studies suggesting that live kidney donors may have higher rates of end-stage renal disease in the long term compared with otherwise similar healthy persons highlights the critical importance of pre-donation evaluation of renal function and structure, and careful application in donor selection criteria. The quality of organs from living donors may also affect recipient outcomes. Because donor kidney function, histology, and anatomy pertain to the quality of the donated organ, living donor characterization of the factors associated with these features is important to the donor as well as the recipient.
\end{abstract}

Keywords Renal transplant $\cdot$ Living donors $\cdot$ Living kidney recipient · Kidney structure · Graft function · Outcomes of living donation

\section{Introduction}

Kidney transplantation is the best treatment for patients with end-stage renal disease because recipients of living

This article is part of the Topical Collection on Live Kidney Donation

Z. S. Zaky • S. Gebreselassie • E. D. Poggio $(\square)$

Department of Nephrology and Hypertension, Glickman Urological

and Kidney Institute, Cleveland Clinic, 9500 Euclid Avenue,

Cleveland, OH 44195, USA

e-mail: poggioe@ccf.org kidney donors fare better than recipients of deceased organ donors. However, the demand for organs remains high and, therefore, the use of organs from higher risk deceased donors (expanded criteria donors and donors after cardiac death) has become a commonly accepted practice despite the lower expected long-term recipient outcomes. Analogously, criteria to accept prospective living kidney donors have evolved, with more transplant centers accepting living donors with "expanded criteria or isolated medical conditions" [1]. Importantly, this evolution is predicated on assumptions of short- and longer-term safety for the living donor. The spectrum of health in accepted donors with isolated medical abnormalities has ranged from subtle metabolic abnormalities to early pre-clinical disease states that may portend future risk [2]. In fact, contemporary donors are older, heavier, and carry more risk factors for chronic kidney disease than donors in earlier generations [3-5]. Additionally, recent data suggesting that live kidney donors have higher rates of end-stage renal disease in the long-term compared with otherwise similar healthy persons $[6 \bullet \bullet, 7]$ highlights the importance of careful predonation selection, including assessment of renal function and structure as critical components of the donor evaluation.

In contrast to deceased donation where only recipient clinical outcomes are of interest, evaluation and selection of living donation must first and foremost consider implications of donor characteristics on their own short- and long-term outcomes. In addition, analogous to deceased donation where organ quality impacts transplant recipient outcomes [8], living donor characteristics also lead to different organ quality. This review provides an overview of the current literature on the determinants of donor kidney function, histology, and anatomy and how these features relate to donor and recipient clinical outcomes. 


\section{Donor Kidney Function and its Implications to the Donor}

Glomerular filtration rate (GFR) is considered the best marker of kidney function [9] and therefore the assessment of GFR is a critical aspect of the donor evaluation. In general practice, kidney function is assessed by the use of creatinine levels or by creatinine-based GFR estimation equations such as the Modification of Diet in Renal Disease or the Chronic Kidney Disease Epidemiology Study equations [10, 11]. However, because of the known limitations of these equations in healthy individuals, such as in the case of living donors, the evaluation of kidney function in this population is commonly performed by either the use of creatinine clearance or the clearances of exogenous markers such as iohexol or iothalamate. In fact, because of the logistical complexities associated with the use of exogenous markers, creatinine clearance is the most commonly used approach in the USA. In a study by Mandelbrot et al. where 131 transplant centers were surveyed regarding their practices when evaluating donors, it was shown that approximately $90 \%$ of centers based their decision making on the use of creatinine clearance, with the other $10 \%$ of centers using the renal clearance of exogenous markers [12]. Whether the use of recently developed creatinine and cystatin C-based GFR estimation equations is applicable in living donor evaluation (i.e., pre-donation GFR) is a matter for future research.

Irrespective of the methodology used to study kidney function, a more clinically important question is the level of predonation renal function at which a donor should be accepted for donation. Ideally, this level or cut-off for safe donation should be derived from studies in which donor and recipient outcomes are evaluated in relation to the pre-donation GFR. While there is published evidence suggesting that donor GFR is an important determinant of allograft outcomes, there is very scarce evidence to recommend a minimum level of kidney function that would leave the donor with sufficient renal function so as to secure a similar life-long risk of kidney disease that is comparable to the healthy population.

Some guidelines recommend that living donors have a GFR of $80 \mathrm{~mL} / \mathrm{min}$ or greater, or alternatively, a kidney function level within two standard deviations of normal for age and sex [13-15]. These guidelines however, do not specify the methodology to be used, whether the proposed cut-off values should be adjusted for body surface area, or provide standardized reference values based on sex, race, and age. Recent practice in the USA reveals that approximately $67 \%$ of transplant centers use the straight cut-off value of $80 \mathrm{~mL} / \mathrm{min}$ to accept donors, while $25 \%$ use an age- and sex-based approach [12]. It is necessary to emphasize that because GFR is known to decline with aging, the lower limit of normal GFR in subjects medically cleared to donate a kidney is variable [4]. This is an important issue to keep in mind when evaluating young donors, as a simple cut-off of $80 \mathrm{~mL} / \mathrm{min}$ may represent low kidney function in such a candidate. Future research should focus on the best approach to determine an acceptable level of GFR that would permit safe organ donation.

Donor nephrectomy represents the loss of approximately $50 \%$ of the nephron mass with a consequent immediate loss of GFR. However, the remaining kidney has the ability to recover a significant percentage of lost function within a relatively short period of time. In healthy subjects, unilateral nephrectomy is followed by a compensatory increase of the contralateral kidney function. This compensation is approximately a $20-40 \%$ increase in GFR from baseline [16-20]. Velosa et al. among others showed that as early as 1-week post-nephrectomy, renal function has recovered to levels slightly lower than those achieved at 6 months post-nephrectomy. Similarly, others have shown that the GFR at 1-year post-donation is similar to the one achieved within a week of nephrectomy [16, 21].

The mechanisms of this compensatory hyperfiltration are complex and determined by several factors [18]. Age and body size may be important determinants of the change in GFR following donation. Kidney function declines with aging; however, while continuous, the decline appears not to be constant [22, 23]. In a cross-sectional study, Rule et al.[24] reported that GFR decreases at a rate of about $4 \mathrm{~mL} / \mathrm{min} /$ $1.73 \mathrm{~m}^{2}$ per decade of life in prospective donors. Poggio et al. [4] also reported that GFR declines at a rate of approximately $4 \mathrm{~mL} / \mathrm{min} / 1.73 \mathrm{~m}^{2}$ per decade of life in donors aged 45 years or younger but the GFR decreases at a faster rate (approximately $8 \mathrm{~mL} / \mathrm{min} / 1.73 \mathrm{~m}^{2}$ per decade) in older donors. Sex and race appear not to be determinants of GFR.

Some investigators hypothesized that post-donation GFR recovery is dependent on pre-donation GFR, which as mentioned above declines with age, while others suggested that kidneys from older donors have a decreased in "renal reserve capacity" that would manifest as impaired kidney function following nephrectomy. Studies by Velosa et al. as well as by Saxena et al. showed that, although aging subjects have a lower absolute baseline GFR, they do not necessarily lose the adaptive hyperfiltration capacity post-nephrectomy. This suggests that post-nephrectomy GFR appears to depend mostly on the pre-nephrectomy kidney function $[18,19]$. Furthermore, the work by Tan et al. provides some mechanistic insights into this hypothesis. Using morphometric analysis of renal histology and function of donors aged younger than 45 years compared with donors aged older than 55 years, the investigators showed that the determinant of postnephrectomy GFR recovery is dependent on the number of functional glomeruli rather than the hyperfiltration capacity of the single nephrons. The lower number of glomeruli (glomerulopenia) found in the older donors may explain the lower post-nephrectomy GFR in their study [25].

In contrast, Rook et al. $[26,27]$ reported that while the postnephrectomy GFR may not be affected by age, the postnephrectomy "reserve capacity" of the remaining kidney as 
assessed by low-dose dopamine-induced hyperfiltration was significantly impaired in older donors. Humans may lose renal reserve as they age because of the loss of functional nephrons as a result of glomerulosclerosis and/or renal microvascular disease [28]. In the study by Ohashi et al., nephrosclerosis on implant biopsy but not donor age was independently associated with post-donation GFR change [29]. There is a high level of correlation between age with glomerulosclerosis and therefore GFR, findings that are common in the current living donor population, but it is not yet clear what the implications of these factors are on the long-term outcomes of living donors.

Overweight and obesity are also prevalent in living donors; therefore, the impact of these variables on GFR recovery deserves attention. Rook et al. [26] showed that pre-donation reserve capacity was preserved independent of body mass index (BMI), but post-donation reserve capacity was blunted in overweight and obese donors. Compared with donors with a BMI less than $25 \mathrm{~kg} / \mathrm{m}^{2}$, those with overweight (BMI from 25 to $29.9 \mathrm{~kg} / \mathrm{m}^{2}$ ) and obese donors (BMI greater than $30 \mathrm{~kg} /$ $\mathrm{m}^{2}$ ), post-donation renal reserve capacity was $6.7+/-8.4 \%$, $4.8+/-5.5 \%$, and $1.3+/-5.5 \%$, respectively $(p=0.006)$. Whether reserve capacity following donation is a surrogate marker of long-term risk for suboptimal kidney function is unknown, but caution should be used when evaluating overweight and obese donors or those with metabolic syndrome.

The current definition of chronic kidney disease includes an estimated GFR of less than $60 \mathrm{~mL} / \mathrm{min} / 1.73 \mathrm{~m}^{2}$ for more than 3 months, not an uncommon finding in older donors after nephrectomy. Whether this definition applies to living donors is a matter of debate. In one study where kidney donors were followed for approximately 4 decades, less than $15 \%$ of donors had a measured GFR by iohexol clearance of less than $60 \mathrm{~mL} / \mathrm{min}$ per $1.73 \mathrm{~m}^{2}$, and none had a GFR of less than $30 \mathrm{~mL} / \mathrm{min}$ per $1.73 \mathrm{~m}^{2}$. Approximately $13 \%$ of kidney donors had some degree of microalbuminuria, but none of the patients had both microalbuminuria and a suboptimal GFR [30]. The rate of decline of GFR after donation remained within the expected values observed in healthy individuals, suggesting that there was no added underlying pathophysiologic process other than those observed with aging alone.

\section{Donor Kidney Function and its Implications to the Recipient}

Living donor kidney function is also a key determinant of recipient allograft outcomes. In fact, the work by Norden et al., which has been used to develop kidney donor guidelines, clearly demonstrated that an unadjusted donor GFR as measured by the renal clearance of a radioisotope of at least $80 \mathrm{~mL} / \mathrm{min}$ was associated with significantly higher recipient graft survival compared with lower levels of donor renal function (RR of 2.28, $p=0.014$, for those recipients of donors with unadjusted GFR less than $80 \mathrm{~mL} / \mathrm{min}$ ). Donor GFR has also been associated with recipient graft function, independent of donor age and kidney size. In a study of 104 living donorrecipient pairs, donor GFR as measured by iothalamate clearances was an independent determinant of allograft function at 2 years post-transplant [31]. In this study, recipients of donor GFR of at least $55 \mathrm{~mL} / \mathrm{min} / 1.73 \mathrm{~m}^{2}$ had a 2 -year GFR of $64+/$ $-8 \mathrm{~mL} / \mathrm{min} / 1.73 \mathrm{~m}^{2}$ compared with $46+/-6 \mathrm{~mL} / \mathrm{min} / 1.73 \mathrm{~m}^{2}$ in those receiving lower donor GFR $(p<0.001)$. This observation was also noted in a larger cohort [32].

As previously mentioned, kidney function and age are highly correlated and, therefore, kidneys from older donors are likely to provide a lower GFR potential to the recipient. There are several studies demonstrating the effect of donor age on kidney allograft function and survival. In a study of 154 living donor-recipient pairs, recipients of kidneys from 52 donors who were aged older than 50 years at the time of donation had a lower 2-year graft function compared with kidney recipients of younger donors $(47+/-19$ vs $55+/-18$, $p<0.05)$ [33]. There was also a trend towards higher frequency of slow graft function in recipients of older donors, which might be owing to the fact that predonation GFR was lower among these donors. Although, GFR was lower among recipients of older compared with younger donor grafts, other functional indices (proteinuria, serum potassium and uric acid, hemoglobin, and number of antihypertensives) were not different. Furthermore, despite the lower GFR post-donation, the graft survival was similar between groups, although follow-up was short. In a different study with a longer follow-up, the actuarial graft survival rate was statistically significantly better at 5 years for recipients of organs from donors aged younger than 50 years when compared with recipients of older donors ( $86.2 \%$ vs $73.1 \%, p<0.001)$ [34]. Finally, using data from the OPTN/UNOS, it has been shown that early posttransplantation outcomes were best in recipients of living donors aged younger than 55 years. Recipients of organs from older donors showed inferior 3-year graft survival rates, but similar 3-year patient survival rates [35].

In summary, kidney donor GFR is highly correlated with donor age, and both are important determinants of graft function and outcomes. These concepts are important in the era of pair-exchanged programs and efforts to match donor and recipient's age should be given consideration.

\section{Donor Kidney Size and its Implications to Donor and Recipient Renal Function}

Kidney volume or size in healthy individuals is a surrogate of nephron mass and therefore kidney function. In a cohort of 119 living donors, a strong correlation between the total kidney volume and donor GFR was shown (Pearson $\mathrm{r}=0.71$, $p<0.001)$ [31]. By univariable and multivariable analysis, 
male sex and body surface area or BMI were independently associated with larger kidney volume and higher absolute GFR. A more recent study by Jeon et al. [36] found that the mean total kidney volume in 222 living donors (Asian population) was $312 \pm 51 \mathrm{cc}$ (range 190-459) and mean volume in men was approximately $50 \mathrm{cc}$ larger than in women. However, after kidney volume was corrected for body surface area there was no sex difference, analogous to what it is known about GFR where there is no or minimal difference in corrected GFR between sexes. Similar findings were later reported by another single-center study [37].

After nephrectomy the remaining kidney undergoes a compensatory hypertrophy, which in fact may explain the known compensatory functional hyperfiltration seen following donation. The increase in volume is mainly in the cortical area and particularly in the proximal tubules [38]. In a non-donor cohort, it was found that the change in contralateral renal parenchymal volume occurred during the first week after nephrectomy and remained stable for more than 6 months [39]. In donor nephrectomy, the mean volume increase of the remaining kidney correlated with the preoperative volume (just like in GFR) and age (higher at ages less than 45 years than at ages greater than 45 years), with no sex difference. Younger age and lower preoperative volume of the remaining kidney were significant predictors of a greater increase in kidney volume. Older age, higher BMI, lower preoperative kidney volume of the remaining kidney, and a lower preoperative GFR were significant factors associated with kidney function recovery [36]. Furthermore, a study of medically complex donors (older age, obese, and hypertensive) compared the capacity of the remaining kidney to compensate after nephrectomy with standard donors. The renal volume hypertrophy after 5 years of nephrectomy was similar to that of the standard donors. The remaining kidney increased in size by $29.3 \%$ and the GFR by $35.6 \%$ [40]. In summary, just as renal function of the remaining kidney adapts to the loss of the donated kidney, a similar effect occurs to kidney size. Importantly, kidney volume highly correlates with function and, therefore, consideration should be given when a large size organ mismatch is present in the setting of paired organ exchange.

A growing body of evidence suggests a positive association between larger donated organs and better recipient graft outcomes in deceased organ transplant [31, 41-44]. This also holds true in living donation, where it has been noted that the donor kidney-recipient body size mismatch ("nephron under dosing") can lead to poor allograft function [44]. Transplantation of donor-recipient pairs with a transplant kidney volume-recipient body weight ratio less than $2 \mathrm{~cm}^{3} / \mathrm{kg}$ was associated with significantly worse graft function [37]. Poggio et al. [31] showed that a transplanted kidney volume greater than $120 \mathrm{cc} / 1.73 \mathrm{~m}^{2}$ was independently associated with better estimated GFR at 2 years post-transplant when compared with recipients of lower transplanted kidney volumes $\left(64+/-19 \mathrm{~mL} / \mathrm{min} / 1.73 \mathrm{~m}^{2}\right.$ vs $48+/-14 \mathrm{~mL} / \mathrm{min} /$ $\left.1.73 \mathrm{~m}^{2}, p<0.001\right)$. Because male individuals have higher average kidney volumes and GFR, the initial GFR for male grafts transplanted into female individuals was statistically significantly higher than for female grafts transplanted into male individuals. At 2 years post-transplantation, estimated GFR was still higher for female recipients of male grafts than for male recipients of female grafts. By univariable and multivariable analyses the observed difference in graft GFR was related to the transplanted volume and not by some other sex effect. In summary, kidney volume or size, especially when there is a negative mismatch with the recipient, may affect allograft function; however, no data on the impact of this variable on graft survival are available.

\section{Kidney Histology in Living Donors}

Implantation renal biopsies provide a unique opportunity to study renal histology in living donors, and to relate demographics factors and clinical characteristics such as metabolic syndrome with histopathologic features. Studies of implant biopsies have revealed a host of clinical characteristics associated with renal histologic features of the living donor that could potentially impact the long-term risk for kidney disease in living donors.

The prevalence of nephrosclerosis (global glomerulosclerosis, tubular atrophy, interstitial fibrosis, and arteriosclerosis) increases with age. In living donors, the prevalence of glomerulo-nephrosclerosis increases linearly with age from $2.7 \%$ for donors aged $18-29$ years, to $73 \%$ for donors aged 70-77 years [45]. Elsherbiny et al. found correlations between some donor characteristics with structural changes in the renal parenchyma [46]. Male sex, high kidney function, albuminuria, family history of renal disease, and high BMI were independently associated with features of nephron hypertrophy (large glomerular volume, large tubular area, and low nonsclerotic glomerular density). Furthermore, history of hypertension and older age were independently associated with higher globally sclerotic glomerular density. In a similar analysis of the same cohort, Chauban et al. showed that the prevalence of moderate-to-severe chronic histologic changes in donors was found in $4.1 \%$ of the donors and that this prevalence was higher in donors aged older than 60 years compared with younger donors ( $11 \%$ vs $3.5 \%, p<0.001)$ and in donors with systolic blood pressure of $140 \mathrm{mmHg}$ or greater when compared with normotensive donors ( $12 \%$ vs $5.7 \%$, $p=0.01$ ) [47]. Short-term follow up in this study (4 months) showed no difference in post-nephrectomy GFR in any particular group. Although not proven, it could be hypothesized that these findings would become more evident after nephrectomy and might contribute to the risk of kidney disease or 
clinically significant dysfunction in the long term; therefore, longer follow-up of these donors is needed.

Overweight and obesity are common in living donors and importantly are correctable conditions. Over the last decades, an increasing number of studies have demonstrated the impact of obesity on renal function and described the poorly defined obesity-related glomerulopathy [48-50]. With pressure to expand the living donor pool to include donors with a higher BMI, it is unclear if those "healthy obese" living donors are at higher risk for kidney disease compared with non-obese counterparts. Rea et al. [51] found in a cohort of 49 obese donors $\left(\mathrm{BMI} \geq 30 \mathrm{~kg} / \mathrm{m}^{2}\right.$ ) and 41 non-obese donors (BMI $\leq 30 \mathrm{~kg} / \mathrm{m}^{2}$ ) that obese living donors had a larger glomerular planar surface area, more tubular dilation, less tubular vacuolization, and a trend towards more arterial hyalinosis than controls. Whether these subtle pathologic features have an impact on the initiation of kidney disease in obese donors is still unknown.

A cohort of 410 living donors [29], including $12 \%$ with metabolic syndrome at donation, found that donors with metabolic syndrome were more likely to have chronic histologic changes defined as glomerulosclerosis, interstitial fibrosis/ tubular atrophy, and any arteriosclerosis. Loss of renal mass as a result of donation led to a lower GFR postnephrectomy in the short term (up to 1 year) in those with metabolic syndrome, and lower GFR recovery at 2 years in those with chronic histologic changes on implant biopsy.

Chronic allograft nephropathy is a common cause of kidney allograft failure [52], and histologically it is characterized by changes that include interstitial fibrosis and tubular atrophy [53]. These changes are associated with reduced renal function and graft survival, and are found in mild forms in protocol biopsies of living donor recipients. These findings increase with time after transplantation ( $71 \%$ of grafts at 2 years) [54]. Thus, it is intuitive that histologic changes in donor implant biopsies would impact recipient graft function (at least in the early post-transplant period) and graft survival; however, given other confounding variables such as alloimmunity and nephrotoxic medications, further studies are needed to determine the true impact of donor histology on long-term recipient allograft survival.

\section{Conclusion}

With the growing need for more organs and the better outcomes observed with living donation, current criteria to accept living donors are evolving. Many factors determine kidney function, histology, and size, and must be considered in the evaluation of the potential donor. The spectrum of renal health of the current living donor is wide. While available evidence supports that living kidney donation is a safe practice, efforts to advance understanding of the long-term clinical implications of predonation renal function and structural characteristics are warranted to avoid unacceptable risks to the donor and to promote good graft outcomes. Considerations of equity in baseline organ size and function are notably relevant to the growing practice of paired kidney exchange. How baseline renal function and structure impacts very long-term (more than a decade) outcomes of the donor and recipient is unknown and deserves further study.

\section{Compliance with Ethics Guidelines}

Conflict of Interest Ziad S. Zaky, Surafel Gebreselassie, and Emilio D. Poggio declare that they have no conflict of interest.

Human and Animal Rights and Informed Consent This article does not contain any studies with human or animal subjects performed by any of the authors.

\section{References}

Papers of particular interest and published recently are highlighted below as:

•• Of major importance

1. Reese PP, Feldman HI, McBride MA, Anderson K, Asch DA, Bloom RD. Substantial variation in the acceptance of medically complex live kidney donors across US renal transplant centers. Am J Transplant. 2008;8(10):2062-70.

2. Young A, Storsley L, Garg AX, Treleaven D, Nguan CY, Cuerden MS, et al. Health outcomes for living kidney donors with isolated medical abnormalities: a systematic review. Am J Transplant. 2008;8(9):1878-90.

3. Davis CL, Cooper M. The state of U.S. living kidney donors. Clin J Am Soc Nephrol. 5(10):1873-80.

4. Poggio ED, Rule AD, Tanchanco R, Arrigain S, Butler RS, Srinivas $\mathrm{T}$, et al. Demographic and clinical characteristics associated with glomerular filtration rates in living kidney donors. Kidney Int. 2009.

5. Taler SJ, Messersmith EE, Leichtman AB, Gillespie BW, Kew CE, Stegall MD, et al. Demographic, metabolic, and blood pressure characteristics of living kidney donors spanning five decades. Am J Transplant. 2013;13(2):390-8.

6.• Mjoen G, Hallan S, Hartmann A, Foss A, Midtvedt K, Oyen O, et al. Long-term risks for kidney donors. Kidney Int. 2014;86(1): 162-7. Discusses possible long-term risks of end-stage renal disease, cardiovascular, and all-cause mortality for kidney donors.

7. Muzaale AD, Massie AB, Wang MC, Montgomery RA, McBride MA, Wainright JL, et al. Risk of end-stage renal disease following live kidney donation. JAMA. 2014;311(6): 579-86.

8. Schold JD, Kaplan B, Baliga RS, Meier-Kriesche HU. The broad spectrum of quality in deceased donor kidneys. Am J Transplant. 2005;5(4 Pt 1):757-65.

9. Levey AS. Measurement of renal function in chronic renal disease. Kidney Int. 1990;38(1):167-84.

10. Levey AS, Coresh J, Greene T, Stevens LA, Zhang YL, Hendriksen $\mathrm{S}$, et al. Using standardized serum creatinine values in the modification of diet in renal disease study equation for estimating glomerular filtration rate. Ann Intern Med. 2006;145(4):247-54. 
11. Levey AS, Stevens LA, Schmid CH, Zhang YL, Castro 3rd AF, Feldman HI, et al. A new equation to estimate glomerular filtration rate. Ann Intern Med. 2009;150(9):604-12.

12. Mandelbrot DA, Pavlakis M, Danovitch GM, Johnson SR, Karp SJ, Khwaja K, et al. The medical evaluation of living kidney donors: a survey of US transplant centers. Am J Transplant. 2007;7(10): 2333-43.

13. Davis CL, Delmonico FL. Living-donor kidney transplantation: a review of the current practices for the live donor. J Am Soc Nephrol. 2005;16(7):2098-110.

14. Delmonico F. A report of the Amsterdam Forum on the Care of the Live Kidney Donor: data and medical guidelines. Transplantation. 2005;79(6 Suppl):S53-66.

15. Delmonico FL, Dew MA. Living donor kidney transplantation in a global environment. Kidney Int. 2007;71(7):608-14.

16. Boner G, Shelp WD, Newton M, Rieselbach RE. Factors influencing the increase in glomerular filtration rate in the remaining kidney of transplant donors. Am J Med. 1973;55(2):169-74.

17. Edgren J, Laasonen L, Kock B, Brotherus JW, Pasternack A, Kuhlback B. Kidney function and compensatory growth of the kidney in living kidney donors. Scand J Urol Nephrol. 1976;10(2):134-6.

18. Saxena AB, Myers BD, Derby G, Blouch KL, Yan J, Ho B, et al. Adaptive hyperfiltration in the aging kidney after contralateral nephrectomy. Am J Physiol Ren Physiol. 2006;291(3):F629-34.

19. Velosa JA, Offord KP, Schroeder DR. Effect of age, sex, and glomerular filtration rate on renal function outcome of living kidney donors. Transplantation. 1995;60(12):1618-21.

20. Poggio ED, Braun WE, Davis C. The science of stewardship: due diligence for kidney donors and kidney function in living kidney donation: evaluation, determinants, and implications for outcomes. Clin J Am Soc Nephrol. 2009;4(10):1677-84.

21. Bock HA, Bachofen M, Landmann J, Thiel G. Glomerular hyperfiltration after unilateral nephrectomy in living kidney donors. Transpl Int. 1992;5 Suppl 1:S156-9.

22. Davies DF, Shock NW. Age changes in glomerular filtration rate, effective renal plasma flow, and tubular excretory capacity in adult males. J Clin Invest. 1950;29(5):496-507.

23. Granerus G, Aurell M. Reference values for 51Cr-EDTA clearance as a measure of glomerular filtration rate. Scand J Clin Lab Invest. 1981;41(6):611-6.

24. Rule AD, Gussak HM, Pond GR, Bergstralh EJ, Stegall MD, Cosio FG, et al. Measured and estimated GFR in healthy potential kidney donors. Am J Kidney Dis. 2004;43(1):112-9.

25. Tan JC, Busque S, Workeneh B, Ho B, Derby G, Blouch KL, et al. Effects of aging on glomerular function and number in living kidney donors. Kidney Int. 2010;78(7):686-92.

26. Rook M, Bosma RJ, van Son WJ, Hofker HS, van der Heide JJ, ter Wee PM, et al. Nephrectomy elicits impact of age and BMI on renal hemodynamics: lower postdonation reserve capacity in older or overweight kidney donors. Am J Transplant. 2008;8(10):2077-85.

27. ter Wee PM, Tegzess AM, Donker AJ. Pair-tested renal reserve filtration capacity in kidney recipients and their donors. J Am Soc Nephrol. 1994;4(10):1798-808.

28. Fuiano G, Sund S, Mazza G, Rosa M, Caglioti A, Gallo G, et al. Renal hemodynamic response to maximal vasodilating stimulus in healthy older subjects. Kidney Int. 2001;59(3):1052-8.

29. Ohashi Y, Thomas G, Nurko S, Stephany B, Fatica R, Chiesa A, et al. Association of metabolic syndrome with kidney function and histology in living kidney donors. Am J Transplant. 2013;13(9): $2342-51$.

30. Ibrahim HN, Foley R, Tan L, Rogers T, Bailey RF, Guo H, et al. Long-term consequences of kidney donation. N Engl J Med. 2009;360(5):459-69.
31. Poggio ED, Hila S, Stephany B, Fatica R, Krishnamurthi V, del Bosque $\mathrm{C}$, et al. Donor kidney volume and outcomes following live donor kidney transplantation. Am J Transplant. 2006;6(3):616-24.

32. Issa N, Stephany B, Fatica R, Nurko S, Krishnamurthi V, Goldfarb DA, et al. Donor factors influencing graft outcomes in live donor kidney transplantation. Transplantation. 2007;83(5):593-9.

33. De La Vega LS, Torres A, Bohorquez HE, Heimbach JK, Gloor JM, Schwab TR, et al. Patient and graft outcomes from older living kidney donors are similar to those from younger donors despite lower GFR. Kidney Int. 2004;66(4):1654-61.

34. Kwon OJ, Kwak JY. The impact of sex and age matching for longterm graft survival in living donor renal transplantation. Transplant Proc. 2004;36(7):2040-2.

35. Gill J, Bunnapradist S, Danovitch GM, Gjertson D, Gill JS, Cecka M. Outcomes of kidney transplantation from older living donors to older recipients. Am J Kidney Dis. 2008;52(3):541-52.

36. Jeon HG, Lee SR, Joo DJ, Oh YT, Kim MS, Kim YS, et al. Predictors of kidney volume change and delayed kidney function recovery after donor nephrectomy. J Urol. 2010;184(3):1057-63.

37. Sikora MB, Shaaban A, Beddhu S, Bourija H, Wei G, Baird B, et al. Effect of donor kidney volume on recipient outcome: does the "dose" matter? Transplantation. 2012;94(11):1124-30.

38. Liu B, Preisig PA. Compensatory renal hypertrophy is mediated by a cell cycle-dependent mechanism. Kidney Int. 2002;62(5):1650-8.

39. Funahashi Y, Hattori R, Yamamoto T, Kamihira O, Moriya Y, Gotoh M. Change in contralateral renal parenchymal volume 1 week after unilateral nephrectomy. Urology. 2009;74(3):708-12.

40. Taner T, Iqbal CW, Textor SC, Stegall MD, Ishitani MB. Compensatory hypertrophy of the remaining kidney in medically complex living kidney donors over the long term. Transplantation. 2014.

41. Giral M, Nguyen JM, Karam G, Kessler M, Hurault de Ligny B, Buchler M, et al. Impact of graft mass on the clinical outcome of kidney transplants. J Am Soc Nephrol. 2005;16(1):261-8.

42. Kasiske BL, Snyder JJ, Gilbertson D. Inadequate donor size in cadaver kidney transplantation. J Am Soc Nephrol. 2002;13(8): 2152-9.

43. Kim YS, Moon JI, Kim DK, Kim SI, Park K. Ratio of donor kidney weight to recipient bodyweight as an index of graft function. Lancet. 2001;357(9263):1180-1.

44. Saxena AB, Busque S, Arjane P, Myers BD, Tan JC. Preoperative renal volumes as a predictor of graft function in living donor transplantation. Am J Kidney Dis. 2004;44(5):877-85.

45. Rule AD, Amer H, Cornell LD, Taler SJ, Cosio FG, Kremers WK, et al. The association between age and nephrosclerosis on renal biopsy among healthy adults. Ann Intern Med. 2010;152(9):561-7.

46. Elsherbiny HE, Alexander MP, Kremers WK, Park WD, Poggio ED, Prieto M, et al. Nephron hypertrophy and glomerulosclerosis and their association with kidney function and risk factors among living kidney donors. Clin J Am Soc Nephrol. 2014;9(11):1892-902.

47. Chauhan A, Diwan TS, Franco Palacios CR, Dean PG, Heimbach $\mathrm{JK}$, Chow GK, et al. Using implantation biopsies as a surrogate to evaluate selection criteria for living kidney donors. Transplantation. 2013;96(11):975-80.

48. Abrass CK. Overview: obesity: what does it have to do with kidney disease? J Am Soc Nephrol. 2004;15(11):2768-72.

49. Weisinger JR, Kempson RL, Eldridge FL, Swenson RS. The nephrotic syndrome: a complication of massive obesity. Ann Intern Med. 1974;81(4):440-7.

50. Kambham N, Markowitz GS, Valeri AM, Lin J, D'Agati VD. Obesity-related glomerulopathy: an emerging epidemic. Kidney Int. 2001;59(4):1498-509.

51. Rea DJ, Heimbach JK, Grande JP, Textor SC, Taler SJ, Prieto $\mathrm{M}$, et al. Glomerular volume and renal histology in obese and non-obese living kidney donors. Kidney Int. 2006;70(9):1636-41. 
52. Matas AJ, Humar A, Gillingham KJ, Payne WD, Gruessner RW, Kandaswamy R, et al. Five preventable causes of kidney graft loss in the 1990s: a single-center analysis. Kidney Int. 2002;62(2):704-14.

53. Solez K, Axelsen RA, Benediktsson H, Burdick JF, Cohen AH, Colvin RB, et al. International standardization of criteria for the histologic diagnosis of renal allograft rejection: the Banff working classification of kidney transplant pathology. Kidney Int. 1993;44(2):411-22.

54. Cosio FG, Grande JP, Larson TS, Gloor JM, Velosa JA, Textor SC, et al. Kidney allograft fibrosis and atrophy early after living donor transplantation. Am J Transplant. 2005;5(5):1130-6. 